\title{
REGIONAL DIFFERENCES IN LABOR DEMAND IN THE UNITED STATES
}

\author{
Rudy Fichtenbaum and John P. Blair*
}

\section{Introduction}

In recent years, scores of studies estimating the elasticity of the demand for labor have been reported (for a review see Hamermesh, 1976). Some of the studies have focused on the elasticity of demand for labor in the economy as a whole (Hamermesh, 1986). Others have focused on particular industries (Cotterill, 1975 and Ashenfelter and Ehrenberg, 1976). A third group of studies has investigated the elasticity of demand for a particular skill (Nadiri and Rosen, 1974). Finally, a fourth group of studies has drawn attention to differences in the elasticity of demand for labor between race/gender/age groups (Grant and Hamermesh, 1981).

These estimates are important to test and verify economic theory. The theory of the firm is based on a model of profit maximization that assumes that when the cost of a resource increases firms will reduce their use of that resource and substitute a relatively cheaper resource. Some have challenged this theory and argued that there is no relationship between incremental changes in factor costs and the demand for the factors (McCombie, 1987).

The estimates also have important implications for policy formation (Hamermesh, 1976; Hamermesh and Grant, 1979; and Killingsworth, 1985). For example, analysis of the employment impact of a change in Old Age, Survivors, Disability and Health Insurance (OASDHI) taxes, employment tax credits, the taxable base for unemployment insurance, or the tax on employer group health insurance premiums requires knowledge of the elasticity of demand for labor. Specific estimates for particular groups of people, whether differentiated by skill, age, race or sex, also are important because they indicate the likely impacts of policies on certain groups of disadvantaged individuals who frequently are of special concern to policy makers.

One area that virtually has been ignored has been interregional in the elasticity of demand for labor. One possible explanation for the lack of attention to regional demand variation is that analysts have assumed implicitly that the elasticity at demand was roughly comparable among regions. However, this assumption does not seem

"Associate Professor of Economics and Professor of Economics, respectively, at Wright State University, Dayton, Ohio. tenable. Differences in industrial mix and demographic consumption could contribute to differences in demand elasticity. The purpose of this study was to fill this important gap in the literature. The particular purpose was to present estimates of the elasticity of demand for labor by region for the manufacturing sector. The hypothesis was that there were significant differences in the elasticity of the demand for labor.

Knowledge of differences in demand elasticity for labor can be extremely important to policy makers at both the state and federal levels. Given the increasing role of states in formulating economic development policy, knowledge of the impact of wage subsidies and taxes in particular state would be extremely useful (Blair and Premus, 1987). At the federal level, knowledge of differences in regional demand elasticities would allow more detailed estimates of the impact of a variety of programs that affect wages and output.

In the first section, a brief theoretical framework for analyzing the demand for labor is presented. In Section II, this framework is used to develop a model that is well suited to analyze interregional differences in the elasticity of demand for labor. In Section III, the data are discussed and empirical estimates of the model are presented. Finally, the article concludes with a discussion of some policy implications of the findings.

\section{The Demand for Labor}

Following Hamermesh (1976) and Killingsworth (1985), it was assumed that the supply of labor and capital is infinitely elastic at prevailing input prices and that labor and capital are normal goods. The demand for labor and the marginal cost in the aggregate are given as follows:

$$
\begin{aligned}
& L=F(w, r, q) \\
& \mu=M(w, r, q)
\end{aligned}
$$

where $L$ is labor, $w$ is the wage rate, $r$ is the cost of capital and $q$ is output. Furthermore, it was assumed that $F_{w}<0$ holding $r$ and $q$ constant; i.e., the substitution effect is negative and $F_{r}>0$, so and increase in the price of capital causes an increase in the demand for labor. $F_{q}>0$ so increases in output necessarily increase the demand for labor, and it also was assumed that, marginal cost, in- 
creases as $w$ and $r$ increase holding output constant.

The demand for market output is given by:

$$
P=H(q)
$$

where $\mathrm{H}_{\mathrm{q}}<0$, implying that the demand curve is downward sloping.

In equilibrium, it was assumed that price is equal to marginal cost, thus:

$$
H(q)=M(w, r, q) \text {. }
$$

Totally differentiating equations 1 and 4 holding $r$ constant yields:

$$
\begin{gathered}
d L=F_{w} d w+F d q \\
H_{q} d q=M_{w} d w+M_{q} d q
\end{gathered}
$$

Dividing both 5 and 6 by dw and substituting 6 into 5 yields the following:

$$
d L / d w=F_{w}+F_{q} M_{w} /\left(H_{q}-M_{q}\right) .
$$

To simplify, it was assumed that production takes place under constant returns to scale, i.e., that $M_{q}=0$. Next, both sides of 7 were multiplied by $w / L$ and the right hand side by $\mathrm{Pq} / \mathrm{Pq}$, and terms were rearranged to obtain the following elasticities:

$$
\mathrm{EL} /\left.\mathrm{Ew}\right|_{\mathrm{r}}=\mathrm{EL} /\left.\mathrm{Ew}\right|_{q, \mathrm{r}}+\left[\mathrm{EL} /\left.\mathrm{Eq}\right|_{\mathrm{w}, \mathrm{r}}[\mathrm{Eq} / \mathrm{EP}]\left[\mathrm{EP} /\left.\mathrm{Ew}\right|_{\mathrm{r}}\right]\right.
$$

where $\mathrm{EL} / \mathrm{Ew} \mathrm{f}_{\mathrm{r}}$ and $\mathrm{Eq} / \mathrm{EP}<0$ and $\mathrm{EL} / \mathrm{Eq} \mathrm{I}_{\mathrm{w}, \mathrm{r}}$ and $\mathrm{EP} / \mathrm{Ew} \mathrm{I}_{\mathrm{r}}$ $>0$.

The first part of equation 8 represents the substitution effect caused by a change in the wage rate, other things being equal. The second part represents the scale effect which contains three components: the change in the demand for labor caused by the change in the demand for output, the change in the quantity demanded resulting from the price change, and the change in price caused by the change in wages. Unfortunately, the empirical data necessary to measure $[\mathrm{Eq} / \mathrm{EP}]$ and $[\mathrm{EP} / \mathrm{Ew} /]$ are not available by region. Following other studies on the demand for labor (Hamermesh, 1976; and Clark and Freeman, 1980), only

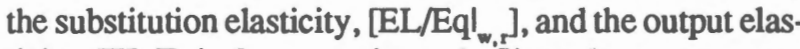
ticity, $\left[\mathrm{EL} / \mathrm{Eq} \mathrm{w}_{\mathrm{w}, \mathrm{s}}\right]$ were estimated. Since the purpose was to examine differences between regions, the findings will be of interest as long as [EL/Eq| $\left.\right|_{w, r}$ ] is not perfectly correlated with $[\mathrm{Eq} / \mathrm{EP}][\mathrm{EP} / \mathrm{Ew} /]$ across regions.

\section{The Empirical Model}

In order to estimate the partial elasticity of demand for labor with respect to wages and output, the following model was used

$$
\ln L_{i t}=\beta_{0}+\beta_{1} \ln w_{i t}+\beta_{2} \ln q_{i t}+\beta_{3} \ln n p_{i t}
$$

where,

$\ln L_{\text {i }}=\log$ of production worker employment in the ith state in year $\mathrm{t}^{1}$

$\ln w_{i}=\log$ of the real wage in the ith state in year $t$,

$\ln \mathrm{q}_{\mathrm{it}}=\log$ of real output in the ith state in year $\mathrm{t}$, and

$\ln \mathrm{np}_{\mathrm{i}}=\log$ of the ratio of nonproduction workers to production workers in the ith state in year $t$.

If the demand for labor is inelastic, a 1 percent increase in the real wage rate, other things being equal, will cause less than a 1 percent decline in the quantity of labor demanded. Since most studies have shown that the demand for labor is inelastic, it was expected that $-1<\beta_{1}<0$ where $\beta_{1}$ is a direct estimate of the substitution elasticity, [(EL/Ew) $\left.\left.\right|_{a, j}\right]$.

An increase in output, other things being equal, will cause an increase in the demand for labor. If the demand for labor with respect to output is inelastic, $\beta_{2}$ should be positive but less than one. Again, the partial elasticity of the demand for labor with respect to output $\left[\left.(E L / E q)\right|_{w}, r\right]$ is estimated directly by $\beta_{2}$.

Finally, the ration of nonproduction workers to production workers was included in the estimating equation. Clark and Freeman (1980) suggested that nonproduction workers might be included in a labor demand equation for production workers. This was done because the labor demand equation estimated was based on a two-factor production function whereas in reality there are other inputs that also must be held constant. Ideally, a complete system of factor demand equation would be specified bu unfortunately the data need for such a specification are unavailable. Since nonproduction workers are a substitute for production workers, as the ration increases the demand for production workers was expected to decrease. Thus, $\beta_{3}$ $<0$ was expected.

Unfortunately, data on interest rates, taxes, depreciation and the cost of capital equipment, that are needed to measure the price of capital directly are unavailable by state. Hamermesh (1976) has argued that failure to include the cost of capital in empirical models imparts a downward bias to estimates of the substitution elasticity but that it 
appears to have no impact on the estimate of the output elasticity. However, ,Clark and Freeman (1980) argue that this result is an artifact of estimating a constrained model in which the wage rate and the price of capital are constrained to have equal and opposite signs. Specifically, they have shown that, in the presence of measurementerror the price of capital should be entered as a separate variable in labor demand equations. When this is done, the substitution elasticity appears to be of the same magnitude in studies regardless of whether they include or exclude the price of capital in labor demand questions. Therefore, it appears that the bias caused by omitting this variable will be minimal.

\section{Data and Empirical Estimates}

The model was estimated using annual data for 1954-83 for the 48 contiguous states. In order to reduce multicollinearity, the states were combined into nine regions and the model was estimated using combined crosssection and time series data. ${ }^{2}$ To control for variation in employment across states, each equation was estimated with a full set of dummy variables for the states in the region (Pindyck and Rubinfeld, 1981). ${ }^{3}$
Data on value added, wages, hours, production workers, nonproduction workers, and the cost of materials were obtained from the Annual Survey of Manufacturers and the Census of Manufacturers. For the years 1979-81, data for individual states were unavailable and were estimated. ${ }^{4}$ The consumer price index and the implicit price deflator for manufacturing were taken from the Economic Report of the President.

Equation 9 was estimated using ordinary least squares. The results are presented in Table 1. For eight of the nine regions, the estimated coefficients on the wage variable were less than one and statistically significant at the 0.01 level. For one region, the wage variable had the wrong sign, but was not significant at the 0.01 level. Overall, these results were consistent with economic theory since they imply that the demand for labor is downward sloping. Furthermore, in all nine regions, the estimated coefficients on the output variable were positive and statistically significant at the 0.01 level. Again, this result was consistent with economic theory, since it implies that increases in output increase the demand for labor.

As expected estimates of [EL/Ewl $\left.\left.\right|_{q,}\right]$ range from 0.721 to -0.231 . The average across the eight regions was $-0.445 .^{5}$ Previous studies of the employment wage elastic-

Table One

Results of Regressions to Estimate Partial Elasticities of Demand for Labor in the United State, by Regions, 1954-1983.

\begin{tabular}{|c|c|c|c|c|}
\hline Regions & $\begin{array}{l}\text { Log Real Wage Rate } \\
\text { (Substitution Elasticity) }\end{array}$ & $\begin{array}{l}\text { Log Real Value Added } \\
\text { (Output Elasticity) }\end{array}$ & $\begin{array}{l}\text { Log (Nonproduction workers } \\
\text { /Production Workers) }\end{array}$ & $\mathrm{R}^{2}$ \\
\hline NENG & $\begin{array}{l}-0.329 \\
(3.50)\end{array}$ & $\begin{array}{l}0.334 \\
(8.74)\end{array}$ & $\begin{array}{l}-0.310 \\
(8.99)\end{array}$ & 0.99 \\
\hline MA & $\begin{array}{l}-0.658 \\
(5.52)\end{array}$ & $\begin{array}{l}0.696 \\
(8.97)\end{array}$ & $\begin{array}{c}-0.721 \\
(17.32)\end{array}$ & 0.98 \\
\hline WNC & $\begin{array}{l}-0.347 \\
(0.378)\end{array}$ & $\begin{array}{c}0.649 \\
(27.10)\end{array}$ & $\begin{array}{l}-0.337 \\
(7.12)\end{array}$ & 0.99 \\
\hline ENC & $\begin{array}{l}-0.231 \\
(4.36)\end{array}$ & $\begin{array}{c}0.558 \\
(18.66)\end{array}$ & $\begin{array}{r}-0.609 \\
(19.50)\end{array}$ & 0.99 \\
\hline SA & $\begin{array}{l}-0.368 \\
(5.13)\end{array}$ & $\begin{array}{l}0.683 \\
(30.38)\end{array}$ & $\begin{array}{l}-0.268 \\
(8.68)\end{array}$ & 0.99 \\
\hline ESC & $\begin{array}{l}0.307 \\
(2.50)\end{array}$ & $\begin{array}{c}0.528 \\
(15.34)\end{array}$ & $\begin{array}{l}-0.278 \\
(5.53)\end{array}$ & 0.98 \\
\hline WSC & $\begin{array}{l}-0.571 \\
(4.99)\end{array}$ & $\begin{array}{c}0.730 \\
(23.36)\end{array}$ & $\begin{array}{l}-0.307 \\
(9.47)\end{array}$ & 0.99 \\
\hline MNT & $\begin{array}{l}-0.721 \\
(7.81)\end{array}$ & $\begin{array}{c}0.740 \\
(35.62)\end{array}$ & $\begin{array}{l}-0.147 \\
(3.27)\end{array}$ & 0.99 \\
\hline PAC & $\begin{array}{l}-0.329 \\
(4.66)\end{array}$ & $\begin{array}{l}0.539 \\
(20.10)\end{array}$ & $\begin{array}{l}-0.166 \\
(4.75)\end{array}$ & 0.99 \\
\hline
\end{tabular}

Note: t-statistics shown in parantheses. 
ity has produced estimates that ranged from -1.09 to -0.04 , with all but one study showing that the substitution effect was inelastic. In fact, the average estimated value of the substitution elasticity for the 14 articles reviewed by Hamermesh (1976) was -0.37 . Clark and Freeman (1980) estimated the substitution elasticity to be between -0.55 and -0.33 , depending on the measure used for the dependent variable and the inclusion of other independent variables. Thus, the findings reported here seem to be consistent with the results in the literature.

The results in Table 1 indicate that the substitution effect was inelastic and that it varied across regions. The Mountain and West South Central states and the MidAtlantic appear to have had significantly higher substitution elasticities than other regions. The similarity of the Mountain and West South Central regions may be due to similarities in industrial composition, higher rural to urban population mixes or demographic factors.

Estimates of the output employment effect [EL/ EqI $]$ ranged between 0.740 and 0.334 with an average of 0.606. Hamermesh (1976) reported that previous studies had estimated the employment output elasticity to between 0.49 and 1.46. Again, Clark and Freeman (1980) estimated the output elasticity to be between 0.53 and 0.77 , depending on the specification of the model. Thus, the estimates here appear to be consistent with the literature. However, once again there was significant variation in the estimates across regions.

The Mountain and West South Central states had the highest output elasticities. Approximately a three-quarter percent increase in employment would be expected for every 1 percent increase in regional output in these regions. In contrast, the New England states had the smallest output effect. These output elasticities indicate the change in labor demanded as a result of a change in output. As was the case with the substitution elasticity, variation in the output elasticity may be accounted for by differences in industrial mix or in demographic makeup.

\section{Conclusion and Policy Implications}

Previous studies measuring substitution and output elasticities have used aggregate national data. This approach implicitly assumed that the elasticities of demand for labor did not differ across regions. However, this paper, has shown that there are significant differences between regions in both substitution and output elasticities. This finding implies that there are significant differences in the total elasticity of demand for labor across regions; therefore, error may be expected when national demand elasticities are used to estimate regional responses to wage and output changes.
These findings regarding interregional variations in the elasticity of demand for labor have important policy implications for both the federal and state governments. At a national level, these results imply that there would be significant differences in the employment impact of across-the-board subsidies designed to create jobs. Federal efforts to subsidize wages would have larger aggregate impacts it they were focused on regions with high substitution elasticities. Furthermore, many other types of subsidies such as Urban Development Action Grants are tied indirectly to the number of jobs created, so these programs also may have the effect of a wage subsidy. Likewise, employment decreases that may follow an increase in the minimum wage would be expected to differ among regions. Regions with low substitution elasticities are likely to be more adversely affected by increases in the minimum wage.

The employment effect of federal trade expansion programs along the lines proposed by Moriarty (1986) likely would would be less effective in regions with low elasticities of demand for output. By similar reasoning, federal procurement policies might have a larger employment impact if they were tilted toward states with high output elasticities, other things equal.

At the state and local levels, policy makers are using a variety of tax and subsidy programs to stimulate employment growth. Again, in order to assess the impact of these policies accurately, geographically disaggregated estimates of the elasticity of demand for labor are needed.

State programs such as on-the-job training of employment tax credits that provide direct of indirect wage subsidies cause employment to increase more in states with high substitution elasticities, other things equal. Such programs will be less effective in the New England and East North Central states because these regions have comparatively inelastic substitution effects. However, New England and the East North Central regions will be more resilient under policies that increase wages. On the other hand, employment in regions with the low substitution elasticities found in the Mountain, West South Central and Mid-Atlantic states will be more adversely affected by government policies that increase costs per employee.

Many State and multi-state regions have adopted export promotion and "buy local" programs designed to increases the demand for the output of the state or region. Increasing employment is one of the major objectives of such expansion programs. Assuming that the programs are equal in their ability to increase exports per dollar of promotional expenditure, the employment impact of such spending will be greater in regions with high output elasticities such as the Mountain states and the South.

This paper has shown regional differences in the 
substitution (EL/Ew/ $\mathrm{q}_{\mathrm{p}}$ ) and output elasticities (EL/EqI of demand for labor. Unfortunately, the data required to estimate changes in quantity demanded as a result of a product price change (Eq/EP) and the other product price changes caused by a change in the wage rate (EP/Ewl) are not available, so a total elasticity for demand could not be estimated. Nevertheless, because of the significant variations in elasticities that were found, the results suggest that both national and state policy could be improved by and accommodation of regional variations in the elasticity of demand of labor.

Future research in this area should concentrate on explaining some of the reasons for the interregional differences in the substitution and output elasticities. At present it is possible only to speculate about these reasons. It was suggested that the industrial mix, the urban rural mix and the demographic mix may explain some of the differences. However, any definitive conclusion in this regard will have to await further research.

\section{Notes}

${ }^{1}$ Production workers were used because the Census of Manufacturers and the Annual Survey of Manufacturers do not publish data on hours for nonproduction workers. Hence, it was impossible to calculated the wage rate for these workers without making ad-hoc assumption about the average number of hours worked.

${ }^{2}$ The nine regions are Census Divisions. Alaska and Hawaii were excluded because they were separate territories during the first five years of the sample period and because their isolation might lead to distortions in estimation.

${ }^{3}$ For space considerations estimates were not included for all the dummy variables. However, a complete set of estimates with all dummy variables is available from the authors upon request.

These data were estimated by regressing the state values on the national values for each series for 1954-1978 and 1982-1983 and using the predicted variables as estimates for the individual states for the missing years.

SThe estimate for the East South Central region was not included in this average because it had the wrong sign and was not significant at the 0.01 level.

\section{References}

Ashenfelter, Orley and Ronald G. Ehrenberg, "The Demand for Labor in the Public Sector," in Labor in the Nonprofit Sectors, ed. Daniel Hamermesh (Princeton, N.J.: Princeton
University Press, 1976).

Blair, John P. and Robert Premus, "Major Features in Industrial Location: A Review," Economic Development Quarterly 1:1 (February 1987):72-84.

Bureau of Census, 1982 Census of Manufacturers, (Washington, D.C.: U.S. Government Printing Office, 1985).

Bureau of Census, Annual Survey of Manufacturers, (various years) (Washington, D.C.: U.S. Government Printing Office).

Clark, Kim B. and Richard B. Freeman, "How Elastic is the Demand for Labor?," Review of Economics and Statistics 62:4 (November 1980):509-20.

Cotterill, Philip, "The Elasticity of Demand for Low-Wage Labor," Southern Economic Joumal 41 (January 1975):52025.

Council of Economic Advisors, Economic Report of the President, (Washington, D.C.: U.S. Government Printing Office, 1986).

Grant, James and Daniel Hamermesh, "Labor Market Competition Among Youths, White Women and Others," Review of Economics and Statistics 63:3 (August 1981):177-96.

Hamermesh, Daniel S., "Econometric Studies for Labor Demand and Their Application to Policy Analysis," Joumal of Human Resources 11:4 (1976):507-25.

Hamermesh, Daniel S., "The Demand for Labor in the Long Run," in Handbook of Labor Economics, ed. Orley Ashenfelter and Richard Layard (Amsterdam: North-Holland, 1986).

Hamermesh, Daniel S. and James Grant, "Econometric Studies of Labor-Labor Substitution and Their Implications for Policy," Journal of Human Resources 14:4 (1979):518-42.

Killingsworth, Mark R., "Substitution and Output Effects on Labor Demand: Theory and Policy Implications," Joumal of Human Resources 20:1 (1985):142-52.

McCombie, J.S.L., "Does the Aggregate Production Function Imply Anything About the Laws of Production? A Note on the Simon and Shaikh Critiques," Applied Economics 19 (1987):1121-1136.

Moriarty, Barry, "Regional Industrial Changes, Industrial Restructuring and U.S. Industrial Policy," Review of Regional Studies 16:3 (Fall 1986):1-10.

Nadiri M. Ishaq and Sherwin Rosen, A Disequilibrium Model of Production, (New York, National Bureau of Economic Research, 1974).

Pindyck, Robert and Daniel L. Rubinfeld, Econometric Models and Economic Forecasts, 2nd edition, New York: McGraw Hill, 1981. 